\title{
TRATAMENTO DA FORMA INDETERMINADA DA DOENÇA DE CHAGAS COM NIFURTIMOX E BENZONIDAZOL
}

\author{
Humberto de Oliveira Ferreira
}

\begin{abstract}
Cem portadores da forma indeterminada da doença de Chagas, com xenodiagnóstico e sorologia positivos, foram tratados no periodo de 1965 a 1985. Destes, metade, com nifurtimox (Bayer) e os outros cinqüenta, com benzonidazol (Roche). Após 24 meses de acompanhamento, dos tratados com nifurtimox, o xenodiagnóstico mostrou-se negativo em 25 (50\%) e as reaçóes sorológicas tornaram-se não reagentes em 3 (6\%) pacientes. Entre os medicados com benzonidazol, no mesmo espaco de tempo, o xenodiagnóstico e a sorologia negativaram-se, respectivamente, em $35(70 \%)$ e em $5(10 \%)$ casos. Os 8 pacientes com xenodiagnóstico negativo também apresentaram reaçōes sorológicas não reagentes. Os tratados com nifurtimox foram acompanhados por tempo médio de 17,3 anos e os medicados com benzonidazol, em média, por 7 anos, $e$ considerados curados.
\end{abstract}

Palavras-chaves: Doença de Chagas. Forma indeterminada. Quimioterapia. Benzonidazol. Nifurtimox.

A eficácia da terapêutica especifica da doença de Chagas parece estabelecida na fase aguda 123457910 . Entretanto, na fase crônica os resultados são pouco animadores 167 .

Trabalhando há muitos anos em área endêmica da tripanosomíase cruzi, pudemos empregar a terapêutica específica da doença, na forma indeterminada, e acompanhar os tratados por vários anos. Por esta razão, parece-nos justificada a apresentação dos resultados obtidos, os quais poderão contribuir para o melhor conhecimento da terapêutica e da evolução na forma em questão da doença.

\section{MATERIAL E MÉTODOS}

Foram acompanhados 100 pacientes, portadores da forma indeterminada da doença de Chagas, em sua maioria crianças e adolescentes, preenchendo os parâmetros referendados na I Reunião de Pesquisa Aplicada em Doença de Chagas ${ }^{8}$. Todos tinham xenodiagnóstico positivo e as reações sorológicas de fixação de complemento, imunofluorescência e hemaglutinação, reagentes.

Os ensaios terapêuticos foram realizados entre 1965 e 1985 tendo sido metade dos pacientes tratada com nifurtimox (Bayer) e os outros cinqüenta pelo benzonidazol (Roche). Vinte destes pacientes eram do Municipio de Água Comprida onde o Prof. Edmundo Chapadeiro havia realizado inquérito epidemiológico sobre a doença de Chagas.

O nifurtimox foi empregado na dose de 15 $\mathrm{mg} / \mathrm{kg}$ peso em crianças e de $10 \mathrm{mg} / \mathrm{kg}$ de peso em

Professor Titular de Pediatria da Faculdade de Medicina do Triângulo Mineiro, Uberaba, MG.

Endereço para correspondència: Prof. Humberto de Oliveira Ferreira, R. Manoel Borges 78, 38010 Uberaba, MG, Brasil.

Recebido para publicação em 14/02/90. adolescentes e adultos, em três tomadas diárias, durante 60,90 e 120 dias, na dependência da tolerância.

O benzonidazol foi utilizado na dose de 5 a 8 $\mathrm{mg} / \mathrm{kg}$ em duas tomadas diárias, durante 60 dias.

A avaliação do efeito terapêutico foi realizada por meio de xenodiagnóstico e das três sorologias convencionais (fixação de complemento, hemaglutinação e imunofluorescência), feitos mensalmente, durante dois anos, em todos os cem casos. Os pacientes que apresentaram o xenodiagnóstico e a sorologia persistentemente negativos, nos 24 meses, tiveram estes exames repetidos, semestralmente, durante 0 número de anos em que foi possivel sua realização.

Para cada xenodiagnóstico foram utilizados 40 triatomíneos.

Considerou-se curado o chagásico tratado, que após pelo menos 5 anos de terapêutica, apresentou testes sorológicos e xenodiagnósticos persistentemente negativos.

\section{RESULTADOS}

Foram observados em alguns casos efeitos colaterais, todos reversíveis, tanto em pacientes tratados com nifurtimox como naqueles medicados com benzonidazol. Com o nifurtimox ocorreram inapetência, perda de peso, náuseas e neuropatia periférica. Este último efeito bem como dermopatia alérgica foram observados nos tratados com benzonidazol.

Após 24 meses iniciais de acompanhamento observou-se que, nos 50 pacientes tratados com nifurtimox, houve negativação do xenodiagnóstico em $25(50 \%)$ e testes sorológicos não reagentes em 3 (6\%). Nos 50 pacientes tratados com benzonidazol, o xenodiagnóstico mostrou-se negativo em $35(70 \%)$ e a sorologia, não reagente, em $5(10 \%)$.

A análise conjunta dos resultados, do xenodiagnóstico e dos exames sorológicos, demonstrou que em 92 dos chagásicos, ao final dos primeiros 24 meses 
de acompanhamento, havia positividade de pelo menos um tipo de exame, indicando o insucesso terapêutico.

Nos oito pacientes restantes, tanto os resultados sorológicos como os xenodiagnósticos, mostraram-se negativos, nos primeiros 24 meses, e assim, permaneceram por um tempo médio de acompanhamento variável de 5 a 18 anos (Tabelas 1 e 2), atualmente não apresentam anormalidades clinicas e têm exames radiológicos (área cardíaca, esôfago e cólon), eletrocardiogramas e ecocardiogramas normais.

O teste exato de Fischer mostrou não haver diferença estatística significativa entre a eficácia das duas drogas empregadas $(\mathrm{p}=0,7150)$.

Tabela 1 - Distribuição dos pacientes segundo tipo de droga utilizado e freqüência de cura.

\begin{tabular}{lcccrr}
\hline Droga & & Cura & & Total & $\begin{array}{c}\% \\
\text { de } \\
\text { cura }\end{array}$ \\
\cline { 2 - 5 } & sim & não & 50 & 6,0 \\
Nifurtimox & 3 & 47 & 50 & 10,0 \\
Benzonidazol & 5 & 45 & 92 & 100 & 8,0 \\
\hline Total & 8 & & & \\
\hline Teste Exato de Fischer: $\mathrm{p}=0.7150$. & & &
\end{tabular}

Tabela 2 - Chagásicos curados após tratamento na forma indeterminada da doença.

\begin{tabular}{|c|c|c|c|c|c|c|c|c|}
\hline \multirow{2}{*}{$\begin{array}{c}\text { Caso } \\
\text { n. }\end{array}$} & \multirow{2}{*}{ Sexo } & \multicolumn{2}{|c|}{ Fase aguda } & \multicolumn{4}{|c|}{ Tratamento na forma ideterminada } & \multirow{2}{*}{$\begin{array}{c}\text { Tempo } \\
\text { controle pós- } \\
\text { terapêutico } \\
\text { (anos) }\end{array}$} \\
\hline & & $\begin{array}{c}\text { Idade em } \\
\text { que ocorreu } \\
\text { (anos) }\end{array}$ & Tratamento & $\begin{array}{l}\text { Idade ao } \\
\text { iniciar } \\
\text { (anos) }\end{array}$ & $\begin{array}{c}\text { Droga } \\
\text { utilizada }\end{array}$ & $\begin{array}{c}\text { Dose } \\
(\mathrm{mg} / \mathrm{kg} / \text { dia })\end{array}$ & $\begin{array}{l}\text { Duração } \\
\text { tratamento } \\
\text { (dias) }\end{array}$ & \\
\hline 1 & $\mathrm{~F}$ & 4 & Spirotrypan & 9 & NF & 15 & 120 & 18 \\
\hline 2 & $\mathrm{~F}$ & 9 & NR & 12 & NF & 15 & 60 & 17 \\
\hline 3 & $\mathrm{~F}$ & 1 & NR & 15 & NF & 15 & 120 & 17 \\
\hline 4 & $\mathrm{~F}$ & 10 & NF & 20 & $\mathrm{BZ}$ & 5 & 60 & 10 \\
\hline 5 & M & 2 & NR & 17 & $\mathrm{BZ}$ & 5 & 60 & 5 \\
\hline 6 & $\mathrm{~F}$ & - & ND & 19 & $\mathrm{BZ}$ & 5 & 60 & 8 \\
\hline 7 & M & - & ND & 15 & $\mathrm{BZ}$ & 5 & 60 & 6 \\
\hline 8 & $\mathrm{~F}$ & - & ND & 11 & $\mathrm{BZ}$ & 5 & 60 & 6 \\
\hline
\end{tabular}

$\overline{\mathrm{F}}=$ feminino $\overline{\mathrm{M}}=$ masculino $\quad \overline{\mathrm{NR}}=$ não realizado $\quad \mathrm{ND}=$ não detectada $\quad \mathrm{NF}=$ nifurtimox $\quad \mathrm{BZ}=$ benzonidazol.

\section{DISCUSSĀO}

$\mathrm{O}$ índice de cura de $8 \%$ por nós encontrado, na forma indeterminada da doença de Chagas, é bastante inferior ao de ate $70 \%$ que obtivemos na fase aguda da endemia 5 .

Em relaçāo a estes estudos devemos frisar que em nossa experiència, no tratamento da fase aguda, a aparente diferença da eficácia do benzonidazol ( $70 \%$ de cura) em relação ao nifurtimox $(46,6 \%)$ não se observou na forma indeterminada ( $10 \%$ e $6 \%$ respectivamente). Apesar de termos empregado seguimento de pelo menos 5 anos, para considerar um chagásico curado, nos parece, que para efeitos práticos, é suficiente o acompanhamento por 24 meses. Isto porque, em nossa experiência, se um chagásico tratado mantém exames sorológicos e xenodiagnóstico, realizados mensalmente, negativos durante 2 anos, estes testes não mais se modificarão.

Diante dos nossos resultados e de outros autores 167 que realizaram ensaios terapêuticos na fase crônica da doença de Chagas, cremos serem necessárias novas pesquisas com o objetivo de obter-se medicamentos mais ativos e com menores efeitos colaterais. Dentre outras razões, pelo fato de admitir$\mathrm{se}^{11}$ a existência nas Américas do Sul e Central de 10 a 20 milhões de pessoas infectadas pelo $T$. cruzi e, de 65 milhões de indivíduos expostos ao risco de contágio.

\section{$S U M M A R Y$}

One hundred patients with the indeterminate form of human chronic Chagas disease were submitted to chemotherapy, 50 with nifurtimox (Bayer) and 50 with benznidazole (Roche) from 1965 up to 1985. After two-year followup there was negativation of xenodiagnosis in $25(50 \%)$ and negativation of serological tests in $3(6 \%)$ of the patients treated with nifurtimox. As for benznidazole there was 35 $(70 \%)$ of xenodiagnosis negativation and $5(10 \%)$ of serological negativation. In 92 patients after a period of 24 month follow-up there was at least one kind of positive test, indicating therapeutic failure. Eight patients with negative xenodiagnosis and serological tests were considered cured. The average follow-up in patients treated with nifurtimox and benznidazole were respectively 17,3 and 7 years.

Key-words: Chagas disease. Indeterminate form. Chemotherapy. Benznidazole. Nifurtimox. 


\section{AGRADECIMENTO}

\section{Ao Professor Euclides Ayres Castilho pelo} estudo estatístico.

\section{REFERÊNCIAS BIBLIOGRÁFICAS}

1. Cançado JR. Tratamento específico da doença de Chagas. In: Cançado JR, Chuster M (ed) Cardiopatia chagásica. 1: edição, Editora Fundação Carlos Chagas, Belo Horizonte p. 327-55, 1985.

2. Cerisola JQ. $O$ estado atual da terapêtica da doença de Chagas. XIII Congresso da Sociedade Brasileira de Medicina Tropical, Brasilia, 1977.

3. Ferreira HO. Tratamento da doença de Chagas (fase aguda) com Bayer 2502. Revista do Instituto de Medicina Tropical de São Paulo 9: 343-345, 1967.

4. Ferreira HO. Ensaio terapêutico-clinico com benzonidazol na doença de Chagas. Revista do Instituto de Medicina Tropical de São Paulo 18: 357-364, 1976.

5. Ferreira HO. Tratamento especifico na fase aguda da doença de Chagas. Jornal-de Pediatria 64: 126-128, 1988.
6. Rassi A. Tratamento etiológico da doença de Chagas. Arquivos Brasileiros de Cardiologia 39: 277-281, 1982.

7. Rassi A, Ferreira HO. Tentativas de tratamento especifico da fase aguda da doença de Chagas com nifurtimox em esquema de duração prolongada. Revista da Sociedade Brasileira de Medicina Tropical 5: 235-262, 1971.

8. I Reunião de Pesquisa Aplicada em doença de Chagas. Validade do conceito da forma indeterminada da doença de Chagas. Revista da Sociedade Brasileira de Medicina Tropical 18: 46, 1985.

9. Richle R Chemotherapy of experimental acute Chagas disease in mice: beneficial effect of Ro 7-1051 on parasitemia and tissue parasitism. XII ${ }^{\text {th }}$ Congress International Therapeutic, Geneva, Switzerland Le Progres Medicale 101: 282, 1973.

10. Richle R. Chemotherapy of experimental acute Chagas disease in mice. Parasitological cure by Ro 7-1051. Proceedings Third International Congress Parasitology. Munich. Germany p. 1296-1297, 1974.

11. Situación de la Enfermidad de Chagas en las Américas. Boletin de La Oficina Sanitaria Panamericana 97: 159-165, 1984. 